\title{
CORONAVIRUS (COVID-19) PANDEMIC CRISIS AND GLOBAL SCENARIO: A REVIEW
}

\section{SHRAVI SINGH ${ }^{1}$, SHREYANSH SINGH ${ }^{2}$, SHAILJA DOBRIYAL ${ }^{3}$, SUNIL KUMAR $^{4}$ AND KUSUM DOBRIYAL ${ }^{5}$}

\author{
${ }^{1}$ Rajshhree Medical College and Research Institute, Bareilly \\ ${ }^{2}$ Rama Medical College, Hospital \& Research Centre, NCR Delhi \\ ${ }^{3}$ Saraswathi Institute of Medical Sciences, UP (Shivalik Apartment, Dehradun) \\ ${ }^{4}$ Department of Zoology, D. A. V. (P.G.) College, Dehradun-248001 \\ ${ }^{5}$ Department of Sanskrit, HNB Garhwal University campus Pauri Garhwal-246001
}

*Corresponding Author Email: shravi.singh1504@gmail.com

Received: 28.11.2020; Revised: 15.12.2020; Accepted: 28.12. 2020

(C)Society for Himalayan Action Research and Development

\begin{abstract}
Novel coronavirus is a new strain that has not been previously found in human beings. Corona Virus Disease-2019 (COVID-19) is a respiratory disease that is originated in Wuhan, China during December, 2019 from where it spread to all over the world in more than 205 countries. Approximately 99 lac peoples were infected, about 1.4 lac death in India out of which more than 94 lac were recovered till December 2020. It was declared pandemic by the World Health Organization in March, 2020. The virus was found to infect people of all ages. It has resulted into more than 7crore infection in people and approximately 16 lac deaths globally till December 2020 and is continuing to cause further mortality. Its mortality rate is high on aged or co-morbid patients suffering from cardiovascular, diabetes, chronic respiratory disease and cancer. In India mortality rate is less than $2 \%$ may be due to genetic variation, immunity, feeding habits and specific socio-cultural traditions. Covid-19 pandemic has changed global economy, medical system and geopolitics. The present communication deals with a review on this pandemic, its current status and future perspectives.
\end{abstract}

Keywords: COVID-19, Microbial diversity, Bio-weapon, Diagnosis, Genetic variations, Herd Immunity, Geopolitics, Traditional Medicine, Global Economy.

\section{Introduction}

Viruses are connecting link between living and non living. Chemically they have genetic material DNA or RNA with protein coat. They are non living outside the body and become active when come in contact of living organism. Among several types of human corona viruses, four types are most common (229E, NL63, OC43, and KHU1) and cause mild to moderate respiratory infections, like the common cold. Other two types, Severe Acute Respiratory Syndrome corona virus (SARS-CoV) and Middle East Respiratory Syndrome corona virus (MERS-CoV), can cause severe respiratory infections (Cheng et. al., 2007). The seventh type COVID-19 or (2019-nCoV) is a new strain recently discovered in China. 
Corona viruses were first discovered in the 1930s when an acute respiratory infection of domesticated chickens was shown to be caused by infectious bronchitis. In 1940s, two other animal corona viruses (mouse hepatitis virus, MHV and transmissible gastroenteritis virus, GTEV) were discovered. The Human corona viruses were discovered in the 1960s as human corona virus 229 E and OC 43 which caused common cold. SARS (severe acute respiratory syndrome) was another corona virus that circulated in China in 2003. MERS (Middle East Respiratory syndrome) was first reported in Saudi Arabia in 2012, which was also caused by a corona virus. The scientist, Zheng-Li Shi, of the Wuhan Institute of Virology, gave the name 'nCoV-2019', which is short for "novel corona virus of 2019". She and her colleagues have been tracing corona virus and has warned that some of them are uniquely suited to cause human pandemics. Three strains of covid-19 (Type-A, Type-B and Type-C) have been identified till now globally.

The corona virus belongs to kingdom Orthornavirae, phylum Pisuviricota, class Pisoniviricetes and family Coronaviridae. It is a single stranded RNA virus with genome size ranging of about $30 \mathrm{~kb}$. It has spherical or pleomorphic enveloped particles with a nucleoprotein within a capsid comprised of matrix protein. The envelope bears club-shaped glycoprotein projections. Coronaviruses are named for these spikes that protrude from their surfaces, resembling a crown or the sun's corona. These envelope glycoproteins are responsible for attachment to the host cell and also carry the main antigenic epitopes, particularly the epitopes recognized by neutralizing antibodies. Most human coronaviruses fall into one of two serotypes: OC43-like and 229E-like. They cause independent epidemics of indistinguishable disease. Coronavirus is made up of 29,903 nucleotides and its core is made up of 27 types of proteins. Several countries are involved in doing research on the structure and DNA sequencing of this virus. According to Professor Martin Hibi, from London school of Hygiene and Tropical Medicine, "For preparing the vaccine, scientists should target the S-protein, which helps in attachment with the human body present in the core of the virus."

The viral envelop consists of a lipid bilayer where the membrane (M), envelop (E) and spike (S) structural proteins are anchored. Inside the envelope, there is nucleocapsid, which is formed from multiple copies of the nucleocapsid protein $(\mathrm{N})$, which are bound to the positive-sense single stranded RNA genome. The lipid bilayer envelope, membrane proteins, and nucleocapsid protect the virus when it is outside the host cell. Genome of novel coronavirus is small thus sequencing and analysis is simple (Lu et. al. 2020). Genome of COVID-19 RNA virus has been sequenced by China, USA, India and France. Council of Scientific and Industrial Research centers as CCMB Hyderabad and Institute of Genomics and Integrative Biology New Delhi are involved in virus genome studies.

Infection begins when the viral spike $(\mathrm{S})$ glycoprotein attaches to its complementary host cell receptor. After attachment, a protease of the host cell cleaves and activates the receptor-attached spike protein. Cleavage and activation allows the virus to enter into the host cell by direct diffusion or endocytosis. The virus particle is uncoated after entry into the cell and its genome enters in to the cell cytoplasm. The host ribosome translates the initial overlapping open reading frame of the virus genome and forms own a long polypeptide, which cleaves itself in to multiple nonstructural proteins. A number of the nonstructural proteins coalesce to form a multi protein replicase- transcriptase complex (RTC). The main replicase transcriptase protein is the RNA dependent RNA polymerase ( $R d R p)$, which is directly involved in the replication and transcription of RNA from RNA strand. 

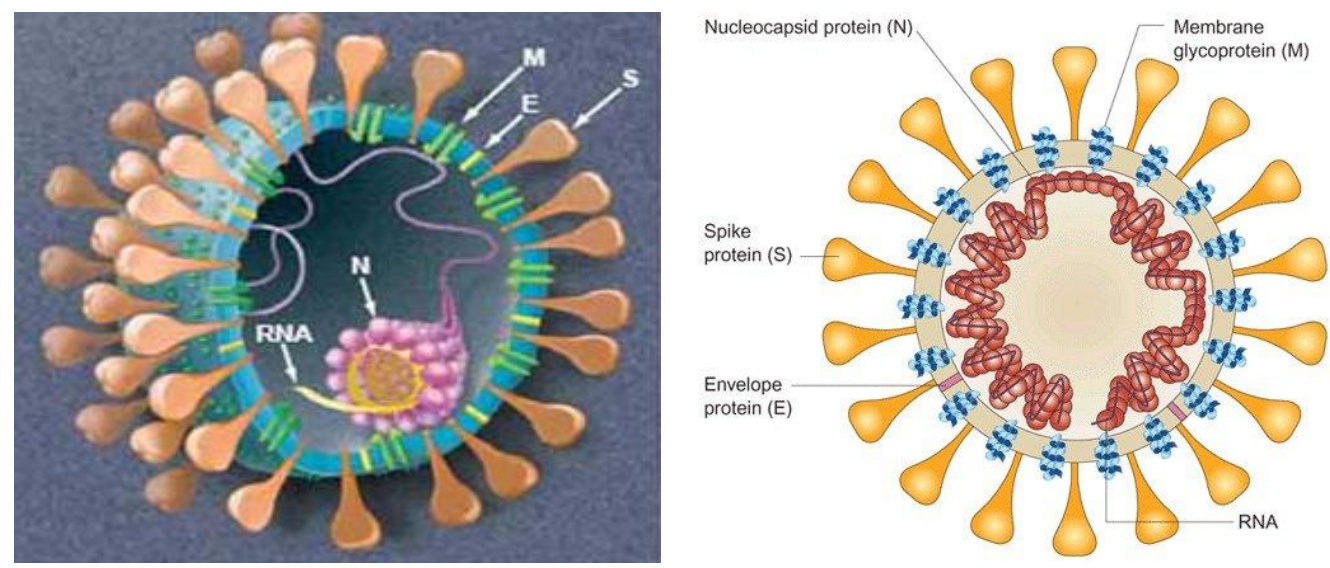

Figure 1. Structure of Coronavirus - COVID-19

The main function of the complex is to replicate the viral genome. RdRp directly mediates the synthesis of negative-sense genomic RNA from the positive-sense genomic RNA. This is followed by the replication of positive-sense genomic RNA from the negative-sense genomic RNA. The other important function of the complex is to transcribe the viral genome. The replicated positive-sense genomic RNA becomes the genome of the progeny viruses. The viral structural proteins $\mathrm{S}, \mathrm{E}$, and $\mathrm{M}$ move along the secretary pathway into Golgi intermediate compartment. There, the M proteins direct most protein-protein interactions required for assembly of viruses following its binding to nucleocapsid. Progeny viruses are then released from the host cell by exocytosis through secretary vesicles.

\section{Human Corona viruses}

Corona viruses vary significantly in risk factor. Some can kill more than $30 \%$ of those infected (MERS$\mathrm{CoV})$, and some are relatively harmless, such as the common cold. The major symptoms of Corona viruses are fever, sore throat and swollen adenoids occurring primarily in the winter and early spring seasons. Further it may cause pneumonia and bronchitis. The human coronavirus discovered in 2003, causes severe acute respiratory syndrome (SARS) having a unique pathogenesis because it causes both upper and lower respiratory tract infections (Cheng et. al., 2007). Six species of human corona viruses are known, with one species subdivided into two different strains, making seven strains of human corona viruses altogether. Four of these strains produce the generally mild symptoms like common cold (Human corona virus OC43 of genus $\beta-\mathrm{CoV}$, HCoV-HKU1- $\beta-\mathrm{CoV}, \mathrm{HCoV}-229 \mathrm{E}-\alpha \mathrm{CoV}$ and HCoVNL63- $\alpha \mathrm{CoV}$ ). Three strains (two species) produce symptoms that are potentially severe; all three of these are $\beta-\mathrm{CoV}$ strains (MERS-CoV, SARS-CoV, SARS-CoV-2).

\section{Pathology}

Studies in both organ cultures and human volunteers show that corona viruses are extremely fastidious and grow only in differentiated respiratory epithelial cells. Infected cells become vacuolated, show damaged cilia, and may form syncytia. Cell damage triggers the production of inflammatory mediators, which increase nasal secretion and cause local inflammation and swelling. These responses in turn 
stimulate sneezing, obstruct the airway, and raise the temperature of the mucosa. ARDS (Acute Respiratory Distress Syndrome) is the main cause of death of COVID-19. ARDS is the common immunepathological event for SARS-CoV-2. The main mechanisms for ARDS is the cytokine storm, the deadly uncontrolled systemic inflammatory response resulting from the release of large amounts of proinflammatory cytokines (IFN- $\alpha$, IL-1, IL-6, IL-12, IL-18, IL-33, TNF- $\alpha$, TGF) and chemokines (CCL-2, CCL-3, CCL-5, CXCL-8, CXCL-9, CXCL-10) by immune effecter cells in SARS-CoV-2 infection.

\section{Epidemiology}

The epidemiology of coronavirus colds has been little studied. Waves of infection pass through communities during the winter months, and often cause small outbreaks in families, schools, etc. Immunity does not persist, and subjects may be re-infected, sometimes within a year. The pattern thus differs from that of rhinovirus infections, which peak in the fall and spring and generally elicit longlasting immunity. About one in five colds is due to corona viruses. The virus is usually transmitted via inhalation of contaminated droplets, but it may also be transmitted by the hands to the mucosa of the nose or eyes.

Experts believe that an infected animal may have first transmitted the virus to humans at a market that sold live fish, animals and birds in Wuhan. The market was later shut down and disinfected, making it nearly impossible to investigate which animal may have been the exact origin. Bats are considered a possible source reservoir host, because they have evolved to coexist with many viruses, and they were found to be the starting point for SARS. It is also possible that bats transmitted the virus to an intermediate animal, such as pangolins, which may have then passed on the virus to humans. The outbreak grew because of human-to-human transmission. People infected with the virus produce tiny respiratory droplets when they breathe, talk, cough or sneeze, allowing the virus to travel through the air. Most respiratory droplets fall to the ground within a few feet. People who are in close contact with those infected, particularly family members and health care workers, may catch the virus this way. Virus is very virulent and contagious due to its spike protein. Surface protein of this virus has great affinity to the receptors on the epithelial cells in out respiratory track and that allows it to enter the cell before it is cleared. Lungs and respiratory tract is the site of infection of Covid-19. People may be sick with the virus for 1 to 14 days before developing symptoms. The symptoms of the disease being fever (88\%), dry cough (68\%), fatigue (38\%), coughing up sputum, or phlegm from the lungs (33\%), shortness of breath (19\%), bone or joint pain $(15 \%)$, sore throat $(14 \%)$, headache $(14 \%)$, chills $(11 \%)$, vomiting $(5 \%)$, stuffy nose $(5 \%)$, diarrhea (4\%), swollen eyes (1\%) etc.

COVID-19 is a lower respiratory tract infection, which means that most of the symptoms are felt in the chest and lungs. That's different from colds that bring on an upper respiratory tract infection, where you get a runny nose and sinus congestion. Those symptoms seem to be mostly absent for people with COVID-19, though they're not unheard of. Most people about $80 \%$ recover from the disease without special treatment. Moreover disease can be more vulnerable, serious or fatal in older people with medical conditions as asthma, diabetes, heart and lung disease etc. (WHO 2020). 
Table 1: Epidemiological data of Human corona viruses.

\begin{tabular}{|l|c|c|c|}
\hline \multicolumn{1}{|c|}{ Disease } & MERS & SARS & Covid-19 \\
\hline \multicolumn{1}{|c|}{ Out break } & $2012,2015,2018$ & $2002-2004$ & $2019-2020$ Pandamic \\
\hline Date of first & June & November & December \\
identified case & 2012 & 2002 & 2019 \\
\hline Location of first & Jeddah, & Shunde, & Wuhan, \\
identified case & Saudi Arabia & China & China \\
\hline Age average & 56 & 44 & 56 \\
\hline Sex ratio & $3.3: 1$ & $0.8: 1$ & $1.6: 1$ \\
\hline Confirmed cases & 2494 & 8096 & $1,484,811$ \\
\hline Deaths & 858 & 774 & 88,538 \\
\hline Case fatality rate & $37 \%$ & $9.2 \%$ & $6.0 \%$ \\
\hline
\end{tabular}

\section{Diagnosis}

To test for COVID-19, a health care provider uses a long swab to take a nasal sample. The sample is then sent to a lab for testing. If you're coughing up saliva (sputum), that may be sent for testing. PCR based molecular testing of respiratory tract samples is the recommended method for the identification and laboratory confirmation of COVID-19 cases. COVID-19 molecular diagnostic Test has been evaluated for quality and safety and recommended by WHO. World Health Organization recommends the use of Point of care Immunodiagnostic test for detection of COVID-19 infection. WHO has listed two diagnostic tests for emergency use during COVID-19 pandemic. These are in vitro diagnostic methods based on genesig Real-Time PCR COVID-19 and cobas SARS-CoV-2 Qualitative assay. Rapid Diagnostic Test (RDT) based on the antigen $(\mathrm{Ag})$ detection. It detects the presence of viral proteins (Antigen) expressed by the virus in a sample from the respiratory tract of the patient. The antigen bind to specific antibody fixed on strip and generates a visually detectable signal within 30 minutes (Bunning et. al 2019). Antigen is expressed if virus is replicating actively and test is used in identifying the acute virus infection. Test efficacy depends on time, concentration of virus, specimen collected, processing and onset of disease. The sensitivity of the test is $40 \%$ to $80 \%$.

DBT (Dept. of Biotechnology) with help of Rajeev Gandhi Centre of Biotechnology, Thiruvananthapuram, developed rapid IgG-IgM detection kits for COVID-19. This kit can detect the disease for four days of exposure to the virus through IgG antibodies. RGCT is developing humanized monoclonal antibodies to treat the disease. Centre for Cellular and Molecular Biology, Hyderabad, is an authorized testing centre for COVID-19 cases.

\section{Control Measure of Covid- 19}

Transmission dynamics of Covid-19 is difficult to identify and target risk group. The virus is highly infectious and virulent. It has a long and uncertain transmission window, possibly spanning 10-14 days (David et. al. 2020). Traditional and graduated steps to control infectious disease are as follows:

1. Identification of target or infected group at National, state, regional or cities level. 
2. Restrictive measure like isolation of infected and quarantine of exposed people through physical distancing, self isolation, stay at home orders.

3. Force restriction or mandatory but not rigidly enforced.

4. Coercive state action as fine, warning, refusal of service etc.

5. Lifting of sanction when risk of infection is gone or very low or under control.

\section{Laboratory Examination}

Examination of the patients for diagnosis of the disease include: white blood cell count is normal or decreased in the early phase of the disease. With decreased lymphocyte count, liver enzymes, muscle enzymes, and myohemoglobin levels are increased in some patients. Most patients display elevated Creactive protein, Lactate Dehydrogenase (LDH) levels and erythrocyte sedimentation rate, and normal procalcitonin levels.Severe cases show high D-dimer levels and progressively decreased blood lymphocytes count. Samples from throat swabs (better using nasopharyngeal swab in children), sputum, lower respiratory tract secretions, stool and blood, etc. are tested positive for 2019-nCoV nucleic acids (Chan et. al. 2020).

\section{Chest imaging examination}

Suspected cases or confirmed cases should undertake chest X-ray examination as soon as possible. Chest CT scan is required when necessary. In the early stage of disease, chest images show multiple small plaques and interstitial changes, which are obvious in the lung periphery, further deteriorate to bilateral multiple ground-glass opacity sometimes along with infiltrating shadows. Lung consolidation may occur in severe cases.

Current efforts to fight the COVID-19 pandemic aim to slow viral spread and increase testing, protect healthcare workers from infection and obtain ventilators and other equipments to prepare for a surge if critically ill patients. It seems that healthcare delivery organizations, educators and government leaders should adapt to expand the workforce capacity, meet the patients needs and control pandemic (Erin et al 2020). Currently, specific antiviral medication against COVID-19 is not available. Treatment is directed at relieving symptoms and may include, Pain relievers (Ibuprofen or acetaminophen), cough syrup or medication, rest, fluid intake, symptomatic treatment etc. Anti-malarial drug hydroxychloroquine is found to be effective to some extent in combination with retroviral drugs as Lopinavir, Litonavir. Ebola drug Remdisivir shows promise against COVID-19(ICMR,2020). Remedisivir, anti-viral drug made by US drug maker Gilead Sciences. This drug inhibits the activity of RNA dependent RNA polymerase and reduces the viral growth. RDV is a phosphorramidate prodrug of a 1-cyanosubsituted nucleotide analogue. This drug shows broad spectrum anti-viral activity against RNA viruses (Gordon et. al. 2020). Interferon- $\alpha$ can reduce viral load in the early stage of infection which can help to alleviate symptoms and shorten the course of disease. Based on clinical research and experiences of using interferon- $\alpha$ in treating bronchiolitis, viral pneumonia, acute upper respiratory tract infection, hand foot mouth disease, SARS, and other viral infections in children, the recommended dosage of Interferon- $\alpha$ nebulization is 200,000$400,000 \mathrm{IU} / \mathrm{kg}$ in $2 \mathrm{ml}$ sterile water and the dosage of Interferon- $\alpha 2 \mathrm{~b}$ spray is $8000 \mathrm{IU}$. Ivermectin is also being used for mild infection treatment. 
Other drugs used for the supportive treatment are wide spectrum antibiotics, which cover wide range of Gram positive and Gram negative bacteria, anti-influenza drugs like Arbidol, Oseltamivir, Methylprednisolone (glucocorticoid), immunoglobulin. Psychotherapy also plays a key role in the treatment. Patients showing fear, mood swings, or psychological disorders, active psychological intervention and treatment are needed. DST (Dept. of Science \& Technology) is funding companies to make devices to enrich oxygen supply in air for the treatment of the patients. Department of Biosciences $\&$ Bioengineering is formulating a gel for nasal passage to prevent COVID-19. Plasma therapy has shown some hope in the treatment, yet it is not still promising treatment of the disease. Use of traditional Chinese medicines may have substantial impact on COVID-19 (Cui et. al. 2020).

\section{Role of Angiotensin Converting Enzyme-2}

Tissue specific and circulating components of the Renin-Angiotensin system (RAS) make up a complex intersecting network of regulatory and counter regulatory peptides. ACE cleaves Angiotensin-I into Angiotensin-II, while ACE-2, a homologue of ACE, and functions as an endogenous counter regulator of ACE by hydrolyzing angiotensin-II into angiotensin (1-7). Upon binding to Ang-II type-I receptor, Ang-II causes vasoconstriction, inflammation and apoptosis, Ang (1-7) opposes the effects of Ang-II. Therefore, the balance between ACE and ACE-II levels affect the endogenous ratio of Ang-II:Ang(1-7). Recombinant ACE-II was previously reported to improve pulmonary blood flow and oxygenation in lung injury. Therefore, ACE-II may protect against acute lung injury.

\section{Prognosis and Prevention}

Preliminary data suggests the reported mortality rate ranges from $3 \%$ to $10 \%$ depending on the genetic variation, climate and country. The majority of the fatalities have occurred in patients over 50 years of age. Young children appear to be mildly infected but may serve as a vector for additional transmission. Patients with chronic conditions that affect the immune system, such as lupus and diabetes, are at a higher risk of developing severe complications from coronavirus. This also makes them more vulnerable to getting bacterial, fungal, viral, and parasitic infections in the first place. Immunosuppression, on its own, is more a symptom than a syndrome, which means that people with certain chronic illnesses or genetic disorders tend to have a compromised immune response as a byproduct of the disease. Chronic conditions like HIV, cancer, lupus, Hashimoto's malnutrition, diabetes and rheumatoid arthritis cause immunosuppression. Steroids, chemotherapy, spleenectomy, inherited conditions like SCID (Severe Combined Immunodeficiency), IgA deficiency can also lead to an immune-compromised state. Vigilance about hand hygiene and self-care, sleep, good nutrition, and de-stressing is essential for immunecompromised people. People who are immune-compromised should be much more cautious about 'nonessential' travel and avoid crowds in regions where there is community transmission of coronavirus.

Early protection, early identification, early diagnosis, and early isolation are crucial to combat with Covid-19 outbreaks. Healthcare professionals have been confronted with several pressing challenges since the onset of outbreak. In initial stages, most cases had direct contact with wildlife and human-tohuman transmission had not yet been demonstrated. Not all hospitals had been equipped with sufficiently protective resources. Subsequently, the number of cases who had recent contact with people from Wuhan 
rapidly increased (CDC, 2019). Lockdown, curfew, declaration of red zone, sealing of hotspots of outbreak area, massive airport screening, quarantine, and social distancing are supposed to be norms to control COVID-19 across the globe. Transmission by respiratory droplets and contact can be avoided by covering mouth and nose with mask when coughing or sneezing. Try not to touch mouth, nose, or eyes before cleaning hands thoroughly after returning from public places, after covering the mouth when coughing. Regular disinfecting of usable devices by heating at $56^{\circ} \mathrm{C}$ for $30 \mathrm{~min}, 75 \%$ alcohol or chlorinecontaining disinfectants, and ultraviolet rays should be practiced. Exposure to infection should be strictly reduced by avoiding public transport at epidemic areas, and wearing masks when going to crowded or poorly ventilated public places. When presenting with suspicious symptoms, patients should be taken to a designated hospital for screening. Newborns delivered by infected mothers must complete a pathogen test and be isolated in a single ward or at home according to their medical conditions. Balanced diet, oral health, adequate exercise, regular rest, avoiding excessive fatigue, and boosting immunity are the powerful measures to prevent infection. Vaccination is an effective way to prevent virus infection. The research and development of anti-virus vaccines has been carried out in many countries at present. It is believed that it will be available in the beginning of 2021.

\section{Future Aspects: Treatment, Vaccine\& Mutation}

There is no cure yet for Covid-19. Doctors and scientists are scrambling to find treatments and drugs that can save the lives of infected people and to prevent infection. Antiviral drugs can stop viruses from attacking our cells. Vaccines tend to train the immune system to target a particular feature, such as a protein structure on the shell of the virus. But by continually altering its appearance, our immune systems find it hard to recognize different infections. It is partly why the common cold has been so difficult to develop a vaccine against. A vaccine works by training the immune system to recognize a portion of the virus. This helps to ensure the person receiving the vaccine does not become sick, but they do develop antibodies that work against that virus in any future infection. But getting the right version of the virus to use can often take many attempts. The synthetic DNA used for vaccine preparation is almost identical to the live virus, but it is unable to replicate itself and spread. Herd immunity and vaccines are the future hope in controlling the disease and community transmission. DBT and BIRAC made COVID-19 Research Consortium. Recent International epidemics of corona virus associated illness underscore the urgent medical and public health need for vaccine development and regulatory body approval therapies. Remdesivir and GS-441524 related compounds are abroad spectrum antiviral drug that is now being tested as a potential treatment for covid-19 in international multisite clinical trials (Amirian and Levy 2020).

Another way a vaccine can be developed is by isolating the cells from a patient who has recovered from the disease. According to the "DRAFT landscape of COVID-19 candidate vaccines" released by the WHO on April 4, two vaccines are currently being tested on humans. This include a non replicating viral vector vaccine developed by Can Sino Biological Inc. along with the Beijing Institute of Biotechnology. A non replicating vector vaccine can be developed either using a virus that is killed or a part of the virus. Since it is killed it cannot replicate inside the host, but the antigen triggers our immune system to produce antibodies, which help fight the disease. An update of epidemiological, clinical, preventive and therapeutic evidence and guidelines for the management of COVID-19 has been given (Chan et. al. 2020). 
Himalayan J. Soc. Sci. \& Humanities ISSN: 0975-9891

Vol. 15, (2020) 37-48

DOI: https://doi.org/10.51220/hjssh.v15i1.5

World joins hands for COVID-19 vaccine development (WHO 2020). It is a "landmark collaboration", to fight against the pandemic. The aim is to speed development of safe and effective drugs. France, Germany and South Africa has taken leading roles in the collaboration. 'We are facing a common threat which we can only be defeated with a common approach," says WHO director- general Tedros. A new vaccine BTN 162 developed by BioNTech German company and Pfitzer USA based company is undergoing clinical trials. Bulks of vaccines are under human trials. Some of the important vaccines in advanced phase and released are the SPUTNIK-V from Russia, CANSINO BIOLOGICS developed by Chinese Military Institute, SINOVAC another Chinese vaccine, ASTRAZENECA OXFORD University, BIONTECH Germany, PFIZER USA.COVAXIN is the vaccine being prepared in India by Bharat Biotech in collaboration with ICMR New Delhi and University of Wisconsin-Madison. INDIAN IMMUNOLOGICALS, has made collaboration with Griffith University Brisbane Australia for testing and manufacturing of vaccine. BIOLOGICAL $\mathrm{E}$ has signed deal with USA to manufacture and test the vaccine in India. SINOPHARM Chinese company testing two vaccines (WHO, 2020).Vaccines that have faced trial 1and 2 are mRNA -1273, Ad26.COV2.S, NVX- CoV2373, BBV152(Covaxin), CoVLP, CVnCoV, INO- 4800, EpiVacCorona. Ssome new vaccines under trail areAG0301-COVID-19, LunarCOV19/ARCT-021， COVID-19/aAPC， LV-SMENP-DC， LNP-nCoVsaRNA， GX-19， SCB-2019, COVAX-19, SARS-CoV-2 Sclamp. Vaccines are under human trial and in practice.

\section{World Scenario and Economic Consequences}

India will export anti-malarial drug hydroxychloroquine high in demand globally to US, Brazil and other friendly countries directly not to private companies since product is under prohibited or banned category of export. India has decided to export this drug in sync with its global commitment to deal with the coronavirus pandemic globally.

Table 2: Mortality and infections of COVID-19 in the World upto December 2020.

\begin{tabular}{|l|l|l|l|l|l|l|l|}
\hline \multirow{2}{*}{ S. No. } & \multirow{2}{*}{ Country } & \multicolumn{3}{l}{ May 2020 } & \multicolumn{2}{l|}{ September 2020 } & \multicolumn{2}{l|}{ December 2020 } \\
\cline { 3 - 8 } & & Infections & Death & Infections & Death & Infections & Death \\
\hline 1. & USA & $45,90,301$ & $1,52,500$ & $67,80,905$ & $1,99,000$ & $1,91,59,529$ & $2,98,906$ \\
\hline 2. & China & 83,543 & 4,626 & 85,108 & 4,650 & 89,646 & 4,784 \\
\hline 3. & Italy & $2,43,827$ & 34,881 & $12,32,503$ & 51,630 & $18,42,557$ & 65,606 \\
\hline 4. & France & $1,88,654$ & 29,393 & $19,01,521$ & 47,667 & $25,95,908$ & 58,521 \\
\hline 5. & Britain & $2,89,991$ & 38,875 & $3,75,591$ & 46,625 & $6,84,40,108$ & $15,92,552$ \\
\hline 6. & India & $16,90,560$ & 35,900 & $51,50,000$ & 81,600 & $98,77,203$ & $1,46,500$ \\
\hline 7. & Germany & $1,83,000$ & 8400 & $2,70,000$ & 9,900 & $14,84,845$ & 19,859 \\
\hline 8. & Russia & $7,96,000$ & 11,555 & $11,75,000$ & 19,653 & $25,88,912$ & 45,597 \\
\hline 9. & Brazil & $25,18,800$ & 88,800 & $44,60,000$ & $1,32,000$ & $68,03,540$ & $1,79,962$ \\
\hline World Total & $\mathbf{1 , 6 9 , 6 0 , 0 0 0}$ & $\mathbf{6 , 6 9 , 8 0 0}$ & $\mathbf{2 , 9 6 , 8 0 , 0 0 0}$ & $\mathbf{9 , 3 8 , 5 0 0}$ & $\mathbf{7 , 1 6 , 4 5 , 9 4 0}$ & $\mathbf{1 6 , 5 2 , 6 7 9}$ \\
\hline
\end{tabular}

Due to COVID-19 outbreak the world economy has affected worse and created a biological war like situation. India is working with the United States to secure a dollar swap line that would help in providing an additional comfort in an event of any abrupt outflow of funds. India liquidated its forex assets to 
stabilize the rupee which recent fell below the 76 level against the dollar. India's foreign currency assets had declined by around $\$ 7.50$ billion in two weeks to $\$ 439.66$ billion as on March 27 . According to Reserve Bank of India (RBI) data, 63.7 per cent of India's foreign currency assets or $\$ 256.17$ billion is invested in overseas securities, mainly in the US treasury. If countries like India and China resort to large scale liquidation of their investments, it could push up the yields and interest rates in the US. There is a case for India to get the swap facility from Fed as the economy is facing rough weather due to the coronavirus outbreak. Despite a nationwide lockdown that disrupted the distribution of rugs across the country and fresh prescription generation, pharmaceutical sales in March registered an 8.9 per cent growth. This was primarily on account of panic buying of medicines in the chronic categories. Cardiac therapy drugs saw a 19.8 per cent growth compared to 11 per cent in February. Anti-diabetic too saw a strong growth of 18.2 per cent in March. However, some therapy areas that are driven primarily by fresh prescriptions, like dermatology, gynecology, vaccines, have seen a dip in sales. Coronavirus COVID-19 will have severe economic and geopolitical consequences which will affect international politics, law and relations.

\section{India and the Coronavirus}

On one hand, it would be reckless to let the coronavirus infection spread in India. The state with maximum number of corona virus active cases is Maharashtra, followed by Tamil Nadu, Gujarat, Delhi. So, a lockdown, however harsh, seems like a sensible course of action. It will bring life to a halt, but will presumably save people from getting infected with COVID-19. But, on the other, what happens to the millions who lose their livelihoods, who are pushed to the brink of starvation?

Table 3: Mortality and infections of COVID-19 in India upto December 2020.

\begin{tabular}{|l|l|l|l|l|l|}
\hline \multirow{2}{*}{ S. No. } & \multirow{2}{*}{ State } & September 2020 & \multicolumn{2}{l|}{ December 2020 } \\
\cline { 3 - 6 } & & Infections & Death & Infections & Death \\
\hline 1. & Maharashtra & $2,17,301$ & 9200 & $18,85,341$ & 47,774 \\
\hline 2. & Delhi & $1,02,500$ & 3,416 & $5,96,924$ & 9,706 \\
\hline 3. & Tamil Nadu & $1,18,543$ & 1,160 & $7,94,552$ & 11,809 \\
\hline 4. & Gujarat & 37,736 & 1,900 & $2,22,168$ & 4,095 \\
\hline 5. & Rajasthan & 20,500 & 493 & $2,87,512$ & 2,448 \\
\hline 6. & Madhya Pradesh & 16,500 & 643 & $2,35,957$ & 3,347 \\
\hline 7. & Uttar Pradesh & 29,300 & 827 & $5,86,397$ & 7,944 \\
\hline 8. & Uttarakhand & 3,250 & 43 & 79,509 & 12,95 \\
\hline & India & $\mathbf{8 , 9 0 , 1 4 0}$ & $\mathbf{2 3 , 8 0 0}$ & $\mathbf{9 9 , 0 3 , 9 0 8}$ & $\mathbf{1 , 4 2 , 9 8 5}$ \\
\hline
\end{tabular}

We save hundred lives through the disease but lose two hundred lives through unemployment. Aarogya Setu App has been developed for staying informed and alert against COVID-19. It is a government initiative to develop a digital bridge among the people to fight against Covid-19. Hydroxychloroquine with other antiviral drugs is effective to some extent in treatment of disease. Indian culture, life style, 
climate, feeding habits, yoga and Indian system of medicine "Ayurveda " promote immunity and disease resistance in the body, thus may be helpful in fighting against the disease.

\section{Emergence of a new variant of Corona Virus in UK}

Recently a new variant of Corona virus has been identified in UK (SARS-CoV-2 VUI 202012/01) that appears to spread more quickly, sparking fresh fears that the Covid-19 pandemic may continue to accelerate even as governments begin administering the first vaccine shots (Lovelace and Feuer, December, 2020). According to CDC, though the virus strain appears to transmit more easily, there are no evidences that the new variant makes people sicker or increases the risk of death. The World Health Organization said the mutation was found in 1,108 cases in the U.K. as of Dec. 13. Some other countries, including India, are also under the influence of this new strain.

\section{Conclusion}

This current crisis now offers us a huge opportunity to think of our behavior and to genuinely evolve. We must take this opportunity to learn living far more sustainable lives. To abjure cruelty to Earth's many species and to give nature the respect it is so richly owned. We must reorient our consciousness to enrich, and not to exploit, this natural world, and to enhance, not end, our fellow species' well being. Wuhan emergency is no novel event. Corona virus is the invisible enemy that we have to be careful from and adjust to live with it. It is part of a sequence of related contingencies that will stretch forward into the future as long as current circumstances persist. Current circumstances include a perilous trade in wildlife for food, with supply chains stretching throughout Asia, Africa, the US, and elsewhere. That trade has now been outlawed in China, on a temporary basis. Power and the consequent ecological disturbances increasing viral exchanges, first from animal to human, then human to human, sometimes on a pandemic scale. We invade tropical forests, wild landscapes, cut the trees, kill the animals or cage them and send them to markets. We disrupt ecosystems, and we shake viruses loose from their natural hosts. When that happens, they need a new host. Often, we are it. We are faced with two mortal challenges. Short term: We must do everyone we can to contain and extinguish this nCoV-2019 outbreak. Long term we must remember, when the dust settles that $\mathrm{nCoV}-2019$ was not a novel event that befell us. It was-it is-part of a pattern of choices that we humans are making. Nature performs its own job of balancing and purifying the ecosystem and conservation of biodiversity. We pray from our nature God for the mutation or genetic changes in the microbe to reduce the virulence and expect some effective drug or vaccine from our scientists or researchers. Video conferences, Webinar, hybrid system of education, webex, Zoom meeting and other online apps will be the future methods of interaction. The threat is not yet over and it is likely to be a serious concern in 2021 may be with more and more new variant as the virus has natural tendency of mutation.

\section{References}

Amirian E S and Levy J K (2020).Current knowledge about the antiviral Ramdesivir (GS-5734) and GS441524 as therapeutic options for coronaviruses.One Health, 9. 
Bruning A H L, Leeflang MM G,Vos JM B W, Spijker R, Jong M D and Wolthers KC (2020). Rapid test for influenza, respiratory syncytial virus and other respiratory viruses. Asystemic Review and Meta Analysis.Clinical Infect. Disease, 65, 6, 1026.

CDC (2019) Corona virus disease 2019, Centre for Disease Control and Prevention, 4, 12.

Chan K W, Wong V T and Tang S C W, (2020). An update on the epidemiological, clinical, preventive and therapeutic evidence and guidelines of Integrative Chinese Western Medicine for the management of COVID-19.The Am. J. Chinese Med., (2020), 27.

Cheng VC, Lau SK, Woo PC and Yuen KY (2007). Severe acute respiratory syndrome coronavirus as an agent of emerging and reemerging infection. Clinical microbiology reviews, 20(4), 660.

Cui, H. T., Li, Y. T., Guo, L. Y., Liu, X. G., Wang, L.S.,Bao, J., Zang, Z., and Wen, W. B., (2020). Traditional Chinese medicine for treatment of coronavirus disease: A review. Traditional Med. Research, 5, (2), 65.

David M S, mark A and Hall J D (2020). Disease control, civil liberties and mass testing calibrating restrictions during the Covid-19 pandemic. The New England J. of Medicine., 10, 56.

Erin P F, Pitman P, Frogner B K and Spetz J, (2020). Ensuring and sustaining a pandemic workforce. The New England J. of Medicine, 10, 72.

Gattinoni L, Coppola S, Cressoni M, Busana M, Rossi S and Chiumello D, (2020). Covid-19 does not lead to a "Typical Acute Respiratory Distress Syndrome. Am. J. Respir. Crit. Care Med, 11.

Gordan C J, Tchesnok VE P, Woolner E, Perry J K, Feng J Y, Porter P D and Gotte M (2020). Remedisivir is a direct acting Anti-viral that inhibit RNA dependent RNA polymerase from severe acute respiratory syndrome corona virus2 with high potency. J. Biol. Chemistry, 1.

Liu Y, Dio B, Ren F and Li X (2020). Diagnostic indexof a rapid IgG/ IgM combined antibody testfor SARS-CoV-2019. Journal of Medical Virology, 5, 62.

Lovelace, Berkeley and Feuer Will. (2020). Five things to know about the new Covid strain spreading in the UK. https://www.cnbc.com/2020/12/22/new-covid-strain-5-things-to-know-about-virusspreading-in-the-uk.html

Lu R, Zhao X, Li J, Niu P, Yang B, Wu H, Wang W, Song H, Huang B, Zhu N, Bi Y, Ma X, Zhan F, Wang J, Lin Y, Hu T, Zhou H, Chen J, Meng Y, Wang J, Lin Y, Yuan J, liu W and Tan W, (2020). Genomic characterization and epidemiology of 2019 novel coronavirus implications for virus origin and receptor binding. Lancet, 395, 565.

WHO, (2020).World Health Organization.Coronavirus Disease -2019 (COVID-19),Situation Report 50, 2.

Zhang Wenhong (2020). Prevention and Control of COVID-19. Huashan Hospital Fudan University, China, 72.

Zhou P, Yang X L, Wang X and Hu B (2020). A pneumonia outbreak associated with a new coronavirus of probable bat origin.Nature, 579, 270. 